\title{
Depletion of gaseous polycyclic aromatic hydrocarbons by a forest canopy
}

\author{
S.-D. Choi ${ }^{1}$, R. M. Staebler ${ }^{2}$, H. Li ${ }^{1, *}$, Y. Su ${ }^{1, * *}$, B. Gevao ${ }^{1, * * *}$, T. Harner ${ }^{2}$, and F. Wania ${ }^{1}$ \\ ${ }^{1}$ Department of Physical and Environmental Sciences, University of Toronto Scarborough, Toronto, Ontario, Canada \\ ${ }^{2}$ Science and Technology Branch, Environment Canada, Toronto, Ontario, M3H 5T4, Canada \\ * now at: Worsfold Water Quality Centre, Trent University, Peterborough, Ontario, Canada \\ ** now at: Science and Technology Branch, Environment Canada, Toronto, Ontario, Canada \\ *** now at: Department of Environmental Science, Environment and Urban Development Division, Kuwait Institute for \\ Scientific Research, Kuwait
}

Received: 13 November 2007 - Published in Atmos. Chem. Phys. Discuss.: 8 February 2008

Revised: 26 May 2008 - Accepted: 9 July 2008 - Published: 31 July 2008

\begin{abstract}
Rapid uptake of gaseous polycyclic aromatic hydrocarbons (PAHs) by a forest canopy was observed at Borden in Southern Ontario, Canada during bud break in early spring 2003. High volume air samples were taken on 12 individual days at three different heights $(44.4,29.1$, and $16.7 \mathrm{~m}$ ) on a scaffolding tower and on the forest floor below the canopy $(1.5 \mathrm{~m})$. Concentrations of PAHs were positively correlated to ambient temperature, resulting from relatively warm and polluted air masses passing over the Eastern United States and Toronto prior to arriving at the sampling site. An analysis of vertical profiles and gas/particle partitioning of the PAHs showed that gaseous PAHs established a concentration gradient with height, whereas levels of particulate PAHs were relatively uniform, implying that only the uptake of gaseous PAHs by the forest canopy was sufficiently rapid to be observed. Specifically, the gaseous concentrations of intermediate PAHs, such as phenanthrene, anthracene, and pyrene, during budburst and leaf emergence were reduced within and above the canopy. When a gradient was observed, the percentage of PAHs on particles increased at the elevations experiencing a decrease in gas phase concentrations. The uptake of intermediate PAHs by the canopy also led to significant differences in gaseous PAH composition with height. These results are the most direct evidence yet of the filter effect of forest canopies for gaseous PAHs in early spring. PAH deposition fluxes and dry gaseous deposition velocities to the forest canopy were estimated from the concentration gradients.
\end{abstract}

Correspondence to: F. Wania

(frank.wania@utoronto.ca)

\section{Introduction}

Vegetation constitutes an important environmental reservoir for semi-volatile organic compounds (SOCs) because of high surface coverage ( $80 \%$ of the earth's terrestrial surface) and the presence of hydrophobic lipids and waxes in foliage (Simonich and Hites, 1994a, 1995). A high surface roughness leads to fast uptake of atmospheric SOCs in forest canopies, which have indeed been shown to effectively filter many SOCs, including polycyclic aromatic hydrocarbons (PAHs). Such filtering reduces air concentrations and increases contaminant deposition to the forest floor (Howsam et al., 2001a, b; Matzner, 1984; McLachlan and Horstmann, 1998; Simonich and Hites, 1994b). Model calculations suggest that the filter effect is most efficient for airborne SOCs that have an octanol-air partition coefficient $\log K_{O A}$ between 7 and 11 and an air-water partition coefficient $\log K_{A W}$ above -6 (McLachlan and Horstmann, 1998). Calculations with a regional multimedia fate model indicated that in very large forested areas the average air concentrations of such chemicals may be reduced by efficient dry deposition during the growing season (Wania and McLachlan, 2001). In particular, global scale modeling revealed that the filter effect of boreal deciduous forests may reduce by half the long-range transport of SOCs to the Arctic (Su and Wania, 2005). Despite these field measurements and modeling efforts devoted to quantifying the forest filter effect, the magnitude, variability, and mechanisms of this process remain to be fully characterized.

The gaseous deposition velocity to deciduous forests is clearly one of the most important factors controlling the forest filter effect. Simultaneous measurement of air

Published by Copernicus Publications on behalf of the European Geosciences Union. 
concentrations and bulk deposition below a canopy and at a nearby clearing has been applied to estimate the SOC deposition to forest canopies during an entire growing season (Horstmann and McLachlan, 1998; Su et al., 2007). While these studies can yield long term average gaseous deposition velocities to forests, they only provide indirect evidence of SOC uptake in the canopy and the resulting reduction of air concentrations. They are also unsuitable for chemicals that degrade in the canopy, such as the PAHs (Su et al., 2007). The purpose of this study was to determine concentration gradients of PAHs developing above a forest as a result of their rapid uptake in the canopy. Specifically, the temporal variations of gaseous and particulate PAHs, their vertical profiles and gas/particle partitioning at different heights on a $45 \mathrm{~m}$ scaffolding tower were investigated in a Canadian deciduous forest.

\section{Experimental section}

\subsection{Air sampling}

The sampling site $\left(44^{\circ} 19^{\prime} \mathrm{N}, 79^{\circ} 56^{\prime} \mathrm{W}\right)$, located $75 \mathrm{~km}$ northwest of Toronto on the Canadian Forces Base Borden (Fig. S1 in the supplementary material, http://www.atmos-chem-phys.net/8/4105/2008/

acp-8-4105-2008-supplement.pdf), is a mixed deciduous forest, dominated by red maple (Acer rubrum), trembling aspen (Populus tremuloides), large-tooth aspen (Populus grandidentata), white ash (Fraxinus americana), black cherry (Prunus serotina), and white pine (Pinus strobes). Average canopy height and stand age is $22 \mathrm{~m}$ and 90 years (http://www.smc.ec.gc.ca/arqp/borden_e.cfm), respectively. The terrain is flat and uniform surface characteristics apply to an area of several square kilometers. A $45 \mathrm{~m}$ scaffolding tower in the center of the forest is fully instrumented for measurements of micrometeorological parameters above and within the canopy. The site has previously been used for studies of the exchange of gases between the forest and the atmosphere (Fuentes et al., 1992; Fuentes et al., 1995; Fuentes et al., 1996; Gu et al., 1999; Makar et al., 1999). Details on the continuous flux program can be found in Lee et al. (1999).

Sampling was carried out in spring (24 April-2 June 2003) when PAH uptake in the forest canopy is expected to be largest, due to the appearance of a new, uncontaminated chemical storage compartment during budburst and leaf emergence. The seasonal development of the leaf area index at Borden confirms that our sampling period corresponds to the early growing season (Strong et al., 2004). Three samples at different heights on the scaffolding tower (44.4, 29.1 , and $16.7 \mathrm{~m}$ ) and one sample on the forest floor below the canopy $(1.5 \mathrm{~m})$ were simultaneously taken on 12 individual days using high volume air samplers (Fig. S2). Particulate and gaseous PAHs were collected on Whatman GF/A glass fiber filters (GFF: $203 \times 254 \mathrm{~mm}$ ) and two polyurethane foam plugs (PUF: $80 \mathrm{~mm}$ diameter, $75 \mathrm{~mm}$ long), respectively. Prior to budburst (24 and 25 April), 24-h samples were collected for two continuous days to characterize the situation without the presence of a canopy. While leaves were developing, 24-h samples were collected every three days until leaves were completely developed, which lasted about one month (5 May-2 June). In total, 48 paired PUF and GFF samples were taken. More information on sampling times is presented in the supplementary material (Table S1).

At the same time, eddy covariance fluxes for sensible heat, $\mathrm{CO}_{2}$, and $\mathrm{H}_{2} \mathrm{O}$ were measured at $33 \mathrm{~m}$ using a triaxial sonic anemometer in combination with fast response gas analyzers. In addition to these measurements, data for air temperatures, wind speed and direction, incoming solar radiation, photosynthetically active radiation, and relative humidity were continuously collected above the canopy. All microclimatic and gas concentration measurements were acquired using data loggers, and results were averaged every half-hour.

\subsection{Chemical analysis}

PUFs and GFFs were individually Soxhlet extracted for $16 \mathrm{~h}$ with petroleum ether (PE) and dichloromethane (DCM), respectively. Extracts were concentrated by rotary evaporation, blown down to about $1 \mathrm{~mL}$ with a gentle stream of nitrogen, and then solvent exchanged into iso-octane. Standard solutions of deuterated PAHs $\left(\mathrm{D}_{8}\right.$-naphthalene, $\mathrm{D}_{8}$ acenaphthylene, $\mathrm{D}_{10}$-phenanthrene, $\mathrm{D}_{10}$-fluoranthene, $\mathrm{D}_{10^{-}}$ pyrene, $\mathrm{D}_{12}$-benzo(a)pyrene, $\mathrm{D}_{12}$-benzo(ghi)perylene) were spiked into the samples prior to extraction to check recoveries during extraction and clean-up procedures. Extracts were cleaned and separated into two fractions on a column of $3 \mathrm{~g}$ 100-mesh silicic acid (deactivated with $3 \%$ water) overlaid by $2 \mathrm{~g}$ neutral alumina (deactivated with $6 \%$ water), and topped with $1 \mathrm{~cm}$ of anhydrous sodium sulfate. The column was pre-washed with $30 \mathrm{~mL}$ of DCM and $30 \mathrm{~mL}$ of PE. The sample was eluted with $50 \mathrm{~mL}$ of PE (fraction 1, containing light PAHs) and then with $30 \mathrm{~mL}$ of DCM (fraction 2, containing heavy PAHs). Fractions were reduced to $1 \mathrm{~mL}$ using a rotary evaporator and further blown down to about $0.5 \mathrm{~mL}$ under a gentle stream of nitrogen and solvent exchanged into iso-octane. Mirex (1,3,4-Metheno-2hcyclobuta(cd)pentalene) was added to the sample prior to injection as internal standard.

Sixteen PAHs (naphthalene, acenaphthylene, acenaphthene, and those listed in Table 1) were analyzed by gas chromatography (GC)-electron impact mass spectrometry in the selected ion monitoring mode using an Agilent 6890 GC5973 mass spectrometric detector. The separation was performed on a DB-5MS column $(60 \mathrm{~m} \times 0.25 \mathrm{~mm}$ i.d., $0.10 \mu \mathrm{m}$ film thickness). One $\mu \mathrm{L}$ of samples was injected in splitless mode at inlet temperature of $280^{\circ} \mathrm{C}$. The carrier gas was helium with a constant flow rate of $1 \mathrm{~mL} \cdot \mathrm{min}^{-1}$. Details on GC 
temperature program and the target ions are provided in the supplementary material.

\subsection{Quality assurance and quality control}

Field blanks were collected for every sampling event $(n=12)$. PUF plugs and GFFs were extracted and analyzed for target analytes using the same method as was used for real samples. The method detection limit (MDL) and recoveries for PAHs calculated from field blanks are shown in Table S2. The range of MDL, defined as the mean blank value plus three standard deviations, was $0.1-27.1 \mathrm{pg} \cdot \mathrm{m}^{-3}$ for gaseous PAHs and $0.1-6.5 \mathrm{pg} \cdot \mathrm{m}^{-3}$ for particulate PAHs. Concentrations below the limit of detection were eliminated and the remaining ones were corrected for average blank values, but not corrected for the recoveries of deuterated PAHs. Recovery, calculated using the seven deuterated PAHs, was 65$136 \%$ for gaseous PAHs and 74-154\% for particulate PAHs (Table S2). Breakthrough was checked by separately analyzing front and back PUFs in each of the four samples taken on 6 May, 30 May, and 2 June. Significant fractions of the three most volatile compounds (naphthalene, acenaphthylene, and acenaphthene) on the back PUF indicated breakthrough and they were thus not considered further. Meanwhile, lack of PAH detection on eight back-up GFFs (30 May and 2 June) indicated that an adsorption artifact was not observed.

\subsection{Calculation of turbulent fluxes}

Gas fluxes $\left(\mathrm{pg} \cdot \mathrm{m}^{-2} \cdot \mathrm{s}^{-1}\right)$ between the air and forest canopy can be calculated by the modified Bowen ratio (MBR) method. This method has been widely used for the calculation of air/surface exchange fluxes of mercury vapor, volatile organic compounds, and other trace gases (Doskey et al., 2004; Lindberg et al., 1998; Majewski et al., 1990; Meyers et al., 1996; Schween et al., 1997). Only recently has it found use for semi-volatile pesticides, both to measure volatilization from agricultural soils (Kurt-Karakus et al., 2006) and to quantify air-water exchange fluxes in Lake Superior (Perlinger et al., 2005). To our knowledge, this study is the first application of the modified Bowen ratio method to measuring fluxes of SOCs to a terrestrial surface. The underlying equation is:

Flux $=-K_{\mathrm{C}} \frac{d C}{d z}$

where $K_{C}$ is the eddy diffusivity $\left(\mathrm{m}^{2} \cdot \mathrm{s}^{-1}\right)$ for chemicals, $C$ is concentration $\left(\mathrm{pg} \cdot \mathrm{m}^{-3}\right)$, and $z$ is height $(\mathrm{m})$. It is assumed that the turbulent exchange of heat and chemicals is governed by the same turbulent mechanisms, i.e. $K_{\text {Heat }}$ equals $K_{C}$ (Schween et al., 1997). $K_{\text {Heat }}$ is determined by combining direct eddy covariance flux measurements of sensible heat with the vertical temperature gradient,

$\overline{w^{\prime} T^{\prime}}=-K_{\text {Heat }} \frac{d T}{d z}$
Table 1. Average and range of PAH concentrations in $\mathrm{pg} \cdot \mathrm{m}^{-3}$ BDL means below method detection limit.

\begin{tabular}{|c|c|c|}
\hline & Gas-phase & Particle-phase \\
\hline Fluorene & $\begin{array}{l}450 \\
(91-990)\end{array}$ & $\begin{array}{l}1.3 \\
(\mathrm{BDL}-3.8)\end{array}$ \\
\hline Phenanthrene & $\begin{array}{l}1250 \\
(270-2600)\end{array}$ & $\begin{array}{l}5.9 \\
(\mathrm{BDL}-24)\end{array}$ \\
\hline Anthracene & $\begin{array}{l}82 \\
(\mathrm{BDL}-380)\end{array}$ & $\begin{array}{l}1.7 \\
\text { (BDL-4.8) }\end{array}$ \\
\hline Fluoranthene & $\begin{array}{l}190 \\
(83-440)\end{array}$ & $\begin{array}{l}20 \\
(3.8-72)\end{array}$ \\
\hline Pyrene & $\begin{array}{l}160 \\
(34-410)\end{array}$ & $\begin{array}{l}18 \\
(3.9-56)\end{array}$ \\
\hline Benz(a)anthracene & $\begin{array}{l}5.3 \\
(0.8-20)\end{array}$ & $\begin{array}{l}13 \\
(3.4-43)\end{array}$ \\
\hline Chrysene & $\begin{array}{l}12 \\
(2-34)\end{array}$ & $\begin{array}{l}21 \\
(4.9-61)\end{array}$ \\
\hline Benzo(b)fluoranthene & $\begin{array}{l}5.2 \\
(\mathrm{BDL}-27)\end{array}$ & $\begin{array}{l}31 \\
(3.4-80)\end{array}$ \\
\hline Benzo(k)fluoranthene & $\begin{array}{l}1.3 \\
\text { (BDL-8.2) }\end{array}$ & $\begin{array}{l}14 \\
(\mathrm{BDL}-33)\end{array}$ \\
\hline Benzo(a)pyrene & $\begin{array}{l}0.5 \\
(\mathrm{BDL}-7.5)\end{array}$ & $\begin{array}{l}14 \\
(2.4-39)\end{array}$ \\
\hline Indeno(123,cd)pyrene & $\begin{array}{l}1.4 \\
\text { (BDL-6.6) }\end{array}$ & $\begin{array}{l}27 \\
(6.4-60)\end{array}$ \\
\hline Dibenz(ah)anthracene & $\begin{array}{l}0.05 \\
(\mathrm{BDL}-0.80)\end{array}$ & $\begin{array}{l}7.1 \\
(\mathrm{BDL}-12)\end{array}$ \\
\hline Benzo(ghi)perylene & $\begin{array}{l}1.6 \\
\text { (BDL-6.2) }\end{array}$ & $\begin{array}{l}25 \\
(7.0-54)\end{array}$ \\
\hline$\sum_{13} \mathrm{PAH}$ & $\begin{array}{l}2200 \\
(540-4300)\end{array}$ & $\begin{array}{l}200 \\
(46-520)\end{array}$ \\
\hline
\end{tabular}

where $w$ is the vertical wind component, $T$ is the temperature, and $\overline{w^{\prime} T^{\prime}}$ represents the turbulent sensible heat flux directly measured by the sonic anemometer (CSAT3, Campbell Scientific Corp) at $33 \mathrm{~m}$, determined on a half-hourly basis. The vertical temperature gradient is determined using the temperatures at $43.4 \mathrm{~m}$ and $29.0 \mathrm{~m}$ in an 8-level temperature profile measured with aspirated, radiation-shielded copper-constantan thermocouples. It is also assumed that the chemical undergoes no transformations between the two gradient levels. Strictly speaking, the gradient method can only be used to derive fluxes for time periods when both the vertical eddy diffusivity $K_{C}$ and the concentration gradient $d C / d z$ are constant. This condition is clearly not fulfilled in our case, as sampling took place over continuous 24-h periods, and $K_{C}$ and $d C / d z$ are expected to undergo significant diurnal variability. However, 24-h sampling periods were considered necessary to achieve the precision required to observe statistically significant differences in PAH air concentrations. To nevertheless derive some kinetic information from the data, we made some assumptions about the diurnal variability of PAH air concentrations to at least provide 
(a)

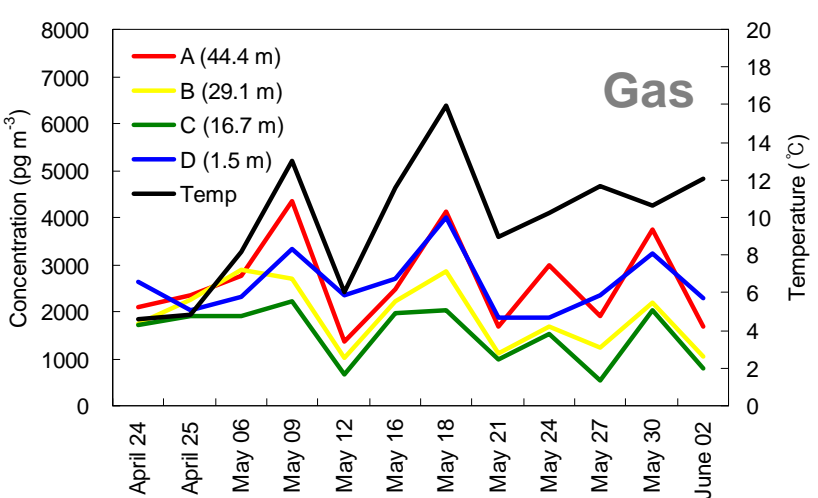

(c)

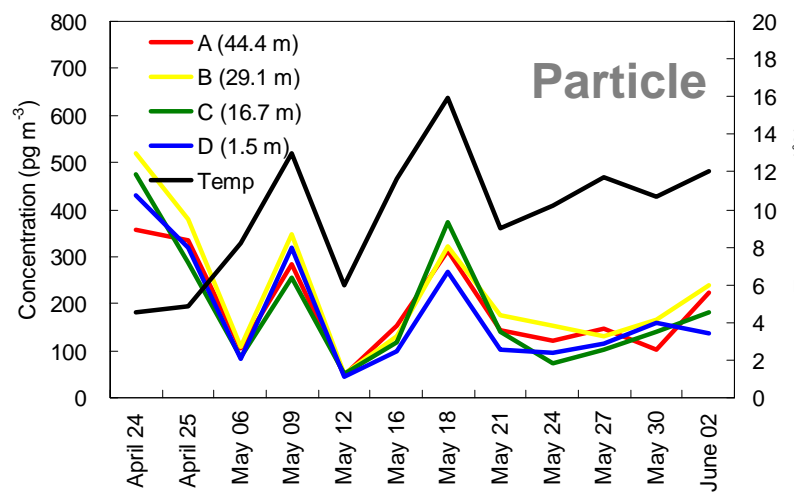

(b)

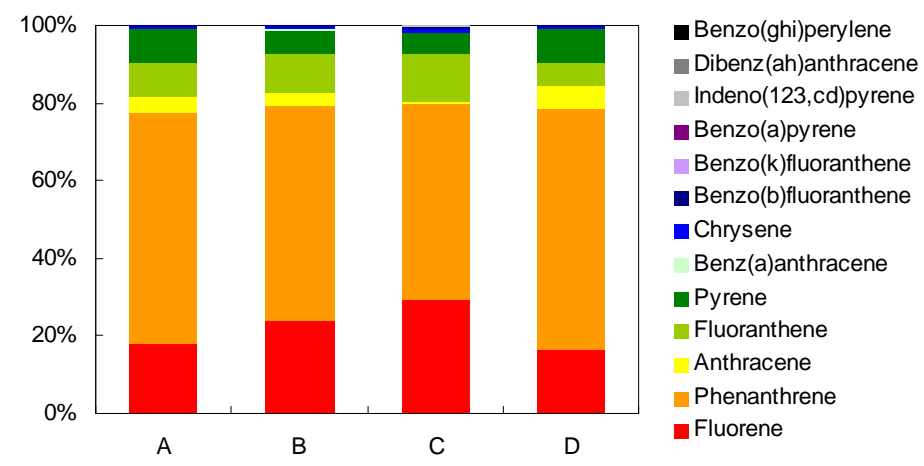

Fig. 1. Temporal variations of the total PAH concentrations $\left(\sum_{13} \mathrm{PAH}\right)$ and the average composition in the gaseous (a, b) and particulate phase (c, d) at different heights. Black lines in (a) and (c) denote average temperatures at height B during the sampling time

a reasonable estimate of the range within which the real flux resides. An overview of the theoretical background of the MBR technique can be found in Businger (1986) and Wesely and Hicks (2000).

\section{Results and discussion}

\subsection{Temporal variations of gaseous and particulate PAHs}

Table 1 lists arithmetic means and ranges of the concentrations of individual PAHs during the sampling period. Concentration data for each air sample are provided in Table S3 and S4. The average concentration of $\sum_{13} \mathrm{PAH}$ (sum of the 13 PAHs listed in Table 1) in this study $\left(2.4 \mathrm{ng} \cdot \mathrm{m}^{-3}\right)$ is lower than the annual average $\left(12.8 \mathrm{ng} \cdot \mathrm{m}^{-3}\right)$ for the same site (derived from 35 measurements from October 2001 to November 2002) presumably because the latter is strongly influenced by high winter time air concentrations ( $\mathrm{Su}$ et al., 2006).
The temporal variation of total gaseous and particulate PAHs at different heights $(A, B, C$, and $D)$ is shown in Fig. 1a and c, respectively. With the exception of the first two days, PAH concentrations at all heights rise and fall in concert with temperature. Especially the particulate PAH concentrations are significantly correlated with temperature $(r=0.85, p<0.01)$. Relatively high concentrations of particulate PAHs on the first two days of sampling, when temperatures were still low, may be related to local emissions associated with residential heating. Air mass origin can explain the correlation between PAH concentrations and temperature during the remainder of the sampling period. Higher concentrations observed on 9 and 18 May are associated with warmer air masses originating in the South and passing over the eastern United States and the Toronto metropolitan area prior to arrival at Borden. Low temperatures and low PAH concentrations, on the other hand, are associated with air masses originating from the Canadian Arctic. Five-day back trajectories, calculated for the sampling days, and wind-rose diagrams are provided in Fig. S3. Whereas the concentrations of particulate PAHs are similar at all four heights (Fig. 1c), those 

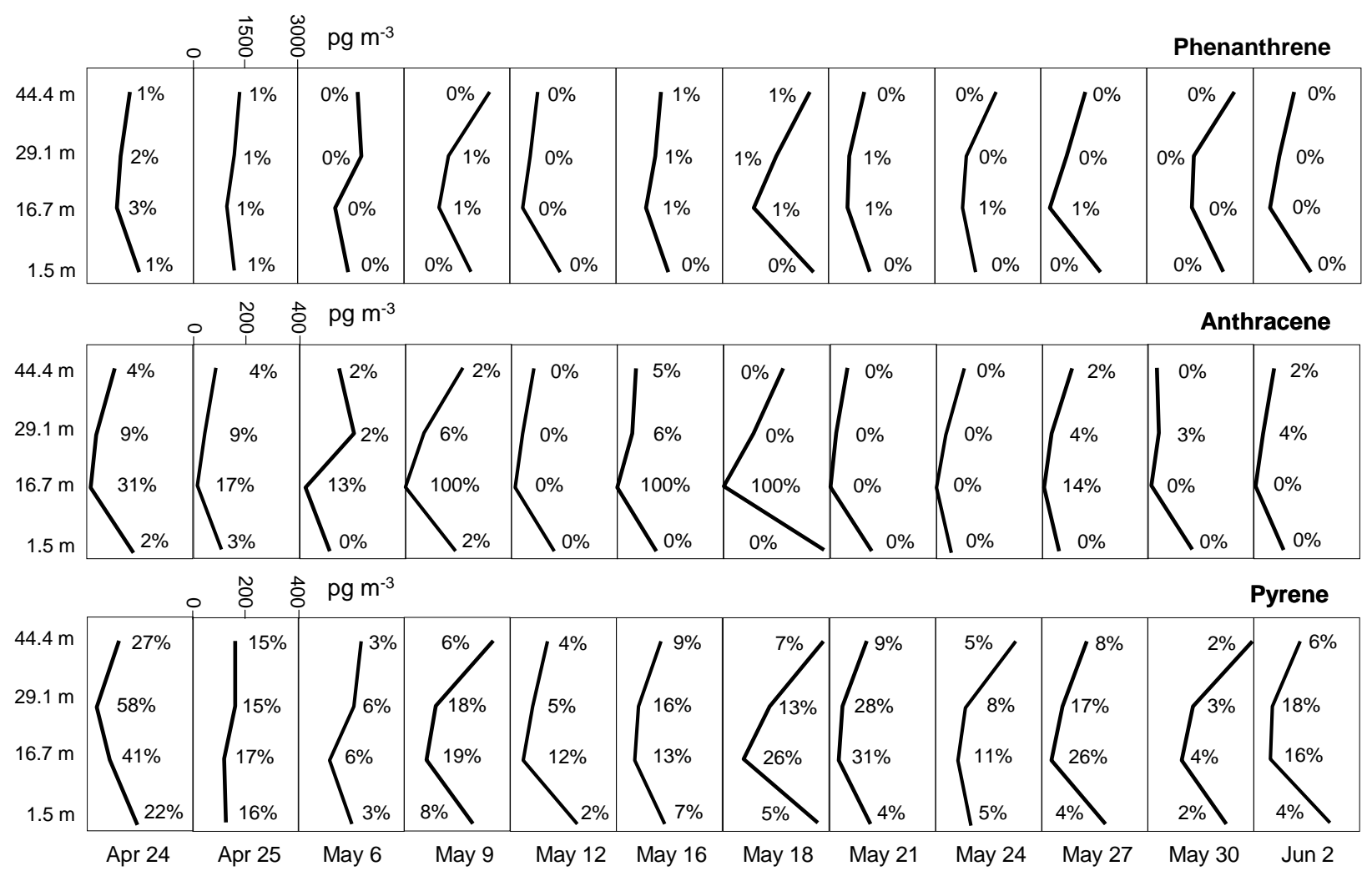

Fig. 2. Vertical profiles of gaseous phenanthrene, anthracene, and pyrene during each sampling day. Percentages of the compounds on particles at the different heights are indicated as well.

of the gaseous PAHs vary with height (Fig. 1a). Generally, the sequence of increasing gas phase concentrations is $C(16.7 \mathrm{~m})<B(29.1 \mathrm{~m})<A(44.4 \mathrm{~m})=D(1.5 \mathrm{~m})$. The average difference between heights $A$ and $C$ is $42 \%$ and $2 \%$ for gaseous and particulate $\sum_{13}$ PAH concentrations, respectively. T-tests for concentration pairs at two different heights confirm significant difference $(p<0.05)$ between $A-B, A-C, B-C, B-D$, and $C-D$. Only gaseous PAH levels at $A$ and $D$ are not significantly different. None of the total and individual concentration differences between particulate PAH concentrations are significant. The average composition of gaseous PAHs also shows subtle differences with height (Fig. 1b). In particular, the contribution of phenanthrene ranges from $51 \%$ (height $C$ ) to $62 \%$ (height $A$ and $D$ ). However, there is no difference in the particulate PAH composition with height (Fig. 1d). These results indicate that only the concentration and composition of gaseous PAHs are influenced by the canopy. Namely, this result agrees with the contention that dry gaseous deposition is the principal process of PAH uptake by vegetation (Simonich and Hites, 1994a).

Theoretically, other processes may contribute to PAH concentrations that vary with height. Whereas differences in photo-oxidant concentrations with height may lead to different loss rates of PAH vapors, the reaction of gas phase
PAHs with hydroxyl radicals proceeds with half lives on the order of $10 \mathrm{~h}$ and more (Brubaker Jr. and Hites, 1998; Kwok et al., 1994) and thus is clearly too slow to explain the observed concentration differences. Reactions with other photo-oxidants, such as ozone, are even slower. Also, photooxidant concentrations at Borden tend to show only minor variations with height and do not have higher values within the canopy (e.g. Makar et al., 1999). During the sampling period, ozone did not show any significant concentration gradient above $16.7 \mathrm{~m}$. Neither were temperature gradients recorded that would be sufficiently large to cause significantly different reaction rates at different elevations or to notably influence the gas/particle partitioning behavior of the PAHs. In any case, the temperature dependence of the $\mathrm{OH}$ radical oxidation of PAHs is very minor (Brubaker Jr. and Hites, 1998).

\subsection{Evidence for the uptake of some gaseous PAHs by the forest canopy}

In Fig. 1a, the levels of gaseous PAHs just above ( $B: 29.1 \mathrm{~m})$ and below $(C: 16.7 \mathrm{~m})$ the top of the canopy are clearly lower than those well above the canopy $(A: 44.4 \mathrm{~m})$ and at ground level $(D: 1.5 \mathrm{~m})$. This vertical gradient for the total gaseous PAHs is mainly due to phenanthrene which is dominant in 
all samples (Fig. 1b). In order to confirm which compounds have vertical gradients, the gas-phase concentrations of intermediate PAHs and particle-phase concentrations of less volatile PAHs were plotted against sampling height (Fig. S4). Gradients with lower concentrations close to the canopy are apparent for gaseous PAHs with three and four aromatic rings, such as phenanthrene, anthracene, and pyrene (Fig. 2). They have $\log K_{O A}$ values of $7.78,7.82$, and 8.93 at $25^{\circ} \mathrm{C}$ (calculated from sub-cooled liquid vapor pressure) (Lei et al., 2002; Xiao and Wania, 2003), which is in the expected range for a pronounced filter effect $\left(7<\log K_{O A}<11\right)$ (McLachlan and Horstmann, 1998). No such gradients were observed for highly volatile PAHs such as fluorene because of the low uptake capacity of the canopy for these PAHs, which may quickly establish equilibrium between air and canopy. Gradients for less volatile PAHs were not observed either because they were strongly associated with particles during the sampling period (Table S5).

Whenever a gradient was observed, the percentage of PAHs on particles increased at the elevations which experienced a decrease in gaseous concentration (Fig. 2). This was most evident in the case of pyrene. This observation suggests that it was mostly the gaseous compounds that were taken up in new foliage and is consistent with the lack of a gradient for the less volatile, particle-bound compounds. The gas/particle partitioning behavior was explored further by relating the fraction in the particle phase (Table S5) to a PAH's vapor pressure. This discussion, which suggested that the gas/particle partitioning behavior above and within the canopy is indeed statistically different, can be found in the supplementary material. Incidentally, the finding that gas phase concentrations change with height, whereas particle phase concentrations do not, implies either that the kinetics of gaseous deposition to the canopy are more rapid than the kinetics of desorption from the particles or that the PAHs in question are not sufficiently desorbable from the particles.

As expected, no strong gradients were observed, especially for phenanthrene and pyrene, on the first two sampling days in late April, which was prior to the emergence of the new foliage at Borden. After budburst, the gradients were maintained throughout May and early June. This suggests that it is indeed the newly emerging foliage which results in the rapid uptake and a decrease in air concentrations. In addition to the gradients above the canopy, inverse gradients were often observed below the canopy, i.e. the PAH levels measured at the forest floor $(1.5 \mathrm{~m})$ were typically higher than the levels within and above the canopy. Again, this phenomenon was only observed for the more volatile PAHs (phenanthrene, anthracene, and pyrene) (Fig. 2), suggesting volatilization from forest litter. In early spring, the potential for such revolatilization may be high because snowmelt has just delivered PAHs that had been deposited over the winter months to the soil surface.
Whether uptake by plants is thermodynamically or kinetically limited depends in part on a chemical's octanol-air partition coefficient $\left(\log K_{O A}\right)$ (Böhme et al., 1999; McLachlan, 1999). Previous studies had identified critical $\log K_{O A}$ values of 9.9 and 9.7 for the gaseous deposition of SOCs to a German and a Canadian deciduous canopy, respectively (Horstmann and McLachlan, 1998; Su et al., 2007). Compounds with $\log K_{O A}$ below that threshold approached equilibrium between air and the forest canopy during a growing season, whereas the uptake of less volatile SOCs is kinetically controlled. In this study, however, even relatively volatile PAHs with $\log K_{O A}<9$ (phenanthrene, anthracene, and pyrene) were likely subject to kinetically limited dry gaseous deposition. This can be explained by the sampling date in early spring, when leaves had just been emerging and had not had time to approach equilibrium with atmospheric PAH levels. In contrast, the $\log K_{O A}$ thresholds in the previous studies were determined from data covering the entire growing season.

\subsection{PAH flux to the forest canopy}

As expected, an investigation of the eddy diffusivities (sensible heat, momentum, and $\mathrm{CO}_{2}$ ) measured during spring 2003 revealed that they were highly variable and in particular that none of the 12 sampling days experienced a "stationary" period that would allow for steady-state flux conditions and thus a direct application of measured eddy diffusivities to individual 24-h measurements. All three eddy diffusivities on average displayed diurnal cycles with minima at night and daytime maxima on the order of $10 \mathrm{~m}^{2} \cdot \mathrm{s}^{-1}$. Due to instrumental difficulties with the $\mathrm{CO}_{2}$ profile during this experiment, $K_{\text {Heat }}$ experienced significantly less noise and was subsequently used as placeholder for $K_{C}$. A median diurnal cycle of $K_{\text {Heat }}$ for the period 20 April-10 June 2003 (Fig. S7) shows a strong diurnal pattern with a noon time maximum (17:00 GMT) and a very low value during night time. The eddy diffusivity derived from the transport of momentum showed a similar range and would produce similar flux estimates.

Level $C$ at $16.7 \mathrm{~m}$ is already within the canopy and should therefore not be used in the quantification of $d C / d z$. It is difficult to assign a defensible eddy diffusivity that applies to a vertical span that includes points above and below the top of the trees. In addition, canopy uptake occurring between levels $B$ and $C$ would invalidate the application of the gradient approach. We therefore used only the concentrations at the highest two levels $A$ and $B$ to calculate $d C / d z$. Fuentes et al. (1996) note that the roughness sub-layer (RSL) limits the applicability of the similarity theory near the top of a forest canopy. However, if we can assume that the vertical distribution of the sources and sinks of PAHs and "heat" are the same and that horizontal homogeneity exists, then both fluxes derived from the gradients would be underestimated to the same extent (relative to a turbulent flux measurement), 
and the effect cancels when the MBR method is applied. Since temperature and PAH concentrations do exhibit similar profiles (Fig. 1), suggesting that the sink for PAH is collocated with the source of the sensible heat, at the elevations with the highest leaf densities, this is thought to be a reasonable assumption. The median 24-h gradients of phenanthrene, anthracene, and pyrene for the 10 sampling days in May and June are 32,3 , and $6 \mathrm{pg} \cdot \mathrm{m}^{-3} \cdot \mathrm{m}^{-1}$, respectively. These gradients are highly variable during the sampling period (Fig. 2), and the flux estimate can only be expected to deliver an order of magnitude estimate.

We have no measurements on whether or how the concentration gradients above the canopy $d C / d z$ changed during the sampling periods. However, we can make different assumptions concerning the diurnal variability of $d C / d z$ to at least provide a rough estimate of a range within which the true flux is likely located. Three diurnal gradient scenarios were used, all sharing the same average value derived from measurements (Fig. S8): Scenario I assumes that $d C / d z$ was constant throughout the 24-h sampling period $(d C / d z$ (day) $=d C / d z$ (night) $)$. Scenario II assumes a decrease of $d C / d z$ by an arbitrary $50 \%$ during the day as a result of increased mixing $(d C / d z$ (day) $=0.5 \cdot d C / d z$ (night)). This scenario approximate a situation where PAHs are advected into the region from elsewhere (MacLeod et al., 2007). A 50\% reduction seems reasonable given the amplitudes shown by MacLeod et al. (2007) for PCBs, and would be partially explained by the increased mixing height during the daytime. Considering the tight relationship between air mass origin and air concentration discussed above, this is not an unlikely scenario. In order to evaluate the influence of the degree of gradient reduction on the uncertainty of PAH fluxes, a third scenario III assumes a reduction of $d C / d z$ by $75 \%(d C / d z$ (day) $=0.25 \cdot d C / d z$ (night) $)$.

By combining the diurnal cycle of the $K_{\text {Heat }}$ (Fig. S7) with the PAH concentration gradients (Fig. S8), we can estimate the average diurnal fluxes for the three gradient scenarios for pyrene, phenanthrene, and anthracene (Fig. S9):

Flux $=-\frac{1}{24} \sum_{i=1}^{24}\left(K_{\text {Heat }}(i) \frac{C_{A}(i)-C_{B}(i)}{z_{A}-z_{B}}\right)$

Where $i$ denotes the hour, $K_{\text {Heat }}(i)$ is the median eddy diffusivity for hour $i$, and $C_{A}$ and $C_{B}$ are the hourly scenario concentrations. $C_{A}$ and $C_{B}$ are constrained by the condition

$\frac{1}{24} \sum_{i=1}^{24} C_{A}(i)=\overline{C\left(z_{A}\right)}$

where the latter is the measured 24-h average.

Note that these fluxes only include the turbulent exchange and do not account for molecular diffusion at night or intermittent transport mechanisms. Maximum uptake is observed during the day in all cases. This pattern results from the diurnal cycle of the diffusivity because the $K$ is close to zero at night.
Table 2. Average fluxes $\left(\mathrm{pg} \cdot \mathrm{m}^{-2} \cdot \mathrm{s}^{-1}\right)$ and dry gaseous deposition velocities $\left(\mathrm{cm} \cdot \mathrm{s}^{-1}\right)$ of intermediate PAHs for different gradient scenarios. A range of fluxes was calculated based on the interquartile range of $K_{\text {Heat }}$ and $d C / d z$.

\begin{tabular}{lllllll}
\hline & \multicolumn{2}{c}{ Scenario I } & \multicolumn{2}{c}{ Scenario II } & \multicolumn{2}{c}{ Scenario III } \\
\hline & Flux & $v_{G}$ & Flux & $v_{G}$ & Flux & $v_{G}$ \\
\hline Phenanthrene & 71 & 7 & 48 & 5 & 35 & 3 \\
& $\left(10-149^{\mathrm{a}}\right)$ & $\left(1-14^{\mathrm{a}}\right)$ & $\left(4-149^{\mathrm{a}}\right)$ & $\left(0-14^{\mathrm{a}}\right)$ & $\left(1-149^{\mathrm{a}}\right)$ & $\left(0-14^{\mathrm{a}}\right)$ \\
Anthracene & 7 & 11 & 5 & 8 & 3 & 5 \\
& $\left(1-9^{\mathrm{a}}\right)$ & $\left(2-14^{\mathrm{a}}\right)$ & $\left(0-9^{\mathrm{a}}\right)$ & $\left(1-14^{\mathrm{a}}\right)$ & $\left(0-9^{\mathrm{a}}\right)$ & $\left(0-14^{\mathrm{a}}\right)$ \\
Pyrene & 14 & 12 & 10 & 8 & 7 & 6 \\
& $\left(2-16^{\mathrm{a}}\right)$ & $\left(2-14^{\mathrm{a}}\right)$ & $\left(1-16^{\mathrm{a}}\right)$ & $\left(1-14^{\mathrm{a}}\right)$ & $\left(0-16^{\mathrm{a}}\right)$ & $\left(0-14^{\mathrm{a}}\right)$ \\
\hline
\end{tabular}

a Fluxes and deposition velocities are capped at a maximum level determined by the 75 th percentile of the reciprocal aerodynamic resistance. The reciprocal aerodynamic resistance represents the physical limit to deposition, equivalent to assuming that the only resistance to transport exists in the surface layer.

The median fluxes for the three intermediate PAHs (Table 2) are in the range of 35 to $71 \mathrm{pg} \cdot \mathrm{m}^{-2} \cdot \mathrm{s}^{-1}$ for phenanthrene, 3 to $7 \mathrm{pg} \cdot \mathrm{m}^{-2} \cdot \mathrm{s}^{-1}$ for anthracene, and 7 to $14 \mathrm{pg} \cdot \mathrm{m}^{-2} \cdot \mathrm{s}^{-1}$ for pyrene. This implies the net dry gaseous deposition of micrograms of PAHs to the canopy per square meter during spring. Scenario I produces higher fluxes than the other scenarios, but they are comparable. For a systematic uncertainty analysis of these results, the uncertainties related to both the measured eddy diffusivity and concentration gradients and the uncertainty introduced by the assumed diurnal cycle scenarios were considered. The uncertainty range for the flux estimates given in Table 2 was estimated by first calculating the interquartile range (25th to 75th percentiles) of hourly $K_{\text {Heat }}$ and of $d C / d z$ for the three diurnal gradient scenarios, and then propagating these into the flux, i.e. $K_{\text {Heat }}(25 \%) \cdot d C / d z(25 \%)$ and $K_{\text {Heat }}(75 \%) \cdot d C / d z(75 \%)$. Spurious negative $K_{\text {Heat }}$ values (suggesting counter-gradient flux) and values greater than $50 \mathrm{~m}^{2} \cdot \mathrm{s}^{-1}$ were removed before analysis. The reciprocal aerodynamic resistance represents the physical limit to deposition, equivalent to assuming that the only resistance to transport exists in the surface layer. Therefore, the flux estimates were limited by the maximum level determined by the 75 th percentile of the reciprocal aerodynamic resistance. As we expected, the estimated uncertainty range suggests that our method can only provide an order of magnitude estimate of the flux (Table 2). The complete uncertainty analysis, which additionally includes estimates using the 5th and 95th percentiles for $K_{\text {Heat }}$ and $d C / d z$ and is summarized in Table S7, suggests that the calculated flux is relatively insensitive to what diurnal variability is assumed for the concentration gradient. 


\subsection{Dry gaseous deposition velocities}

Despite the considerable uncertainty in the fluxes derived in the preceding section, we judged it to be worthwhile to estimate the order of magnitude of dry gaseous deposition velocities to the canopy $\left(v_{G}\right.$ in $\left.\mathrm{cm} \cdot \mathrm{s}^{-1}\right)$ using:

$v_{G}=-\operatorname{Flux} / C_{G}$

where $C_{G}$ is the gaseous concentration of PAHs at level B. The median velocities are on the order of 5 to $10 \mathrm{~cm} \cdot \mathrm{s}^{-1}$ (Table 2). They vary between chemicals, increasing two-fold from phenanthrene $\left(3-7 \mathrm{~cm} \cdot \mathrm{s}^{-1}\right)$ to anthracene and pyrene $\left(5-12 \mathrm{~cm} \cdot \mathrm{s}^{-1}\right)$. Again, we provide ranges indicating the uncertainty of these estimates (see also Table S7). Variability in the deposition velocities of different PAHs would be expected, if they had approached equilibrium between canopy and atmospheric gas phase to a different extent. In general, however we suspect that these three PAHs were still far from equilibrium because sampling occurred very early in the growing season.

The deposition velocities for intermediate PAHs from this study are of the same order of magnitude as, albeit somewhat higher than, those previously reported for SOCs in Borden $\left(2.7 \mathrm{~cm} \cdot \mathrm{s}^{-1}\right)$ (Su et al., 2007) and a German deciduous forest $\left(3.6 \mathrm{~cm} \cdot \mathrm{s}^{-1}\right.$ ) (Horstmann and McLachlan, 1998). It is encouraging that the deposition velocities derived here agree reasonably with those reported previously, at least considering their considerable uncertainty. The latter values are average gross deposition velocities for the entire growing season, and were indirectly determined from differences in total deposition under the canopy and a nearby clearing (Horstmann and McLachlan, 1998), whereas the values reported here are net deposition velocities during the first month after budburst, so perfect agreement can not be expected, especially as gross deposition velocities may vary during the growing season. As long as the PAHs were far from reaching equilibrium between atmospheric gas phase and leaves during that month, net and gross deposition velocities would be similar because revolatilization from the canopy would still be negligible. The high deposition velocities observed in the present study lend further support to the very rapid uptake of PAHs by deciduous forest canopies.

\section{Conclusions}

Rapid uptake of gaseous PAHs by the deciduous forest canopy was observed during bud break in early spring. This conclusion relies on the following evidence:

1. Concentrations of intermediate gaseous PAHs, such as phenanthrene, anthracene, and pyrene, within the canopy were reduced relative to above and below the canopy.
2. When this gradient was observed, the percentage of PAHs on particles increased at the elevations which experienced a decrease in gaseous concentration.

3. No strong gradients were observed prior to the emergence of the new foliage, but the gradients were maintained throughout the sampling period after budburst.

4. The gas/particle partitioning behavior above and within the canopy was statistically different.

These observations suggest that the newly emerging foliage indeed resulted in the rapid uptake of intermediate gaseous PAHs and a decrease in air concentrations.

Average diurnal fluxes and dry gaseous deposition velocities were estimated from the air concentrations measured at the two highest elevations. The net dry gaseous deposition flux of individual PAHs to the canopy was in the range of micrograms per square meter during spring. Deposition velocities were of the same order of magnitude as, albeit somewhat higher than, those previously reported, lending further support to the hypothesis of rapid uptake of SOCs by deciduous forest canopies. This is the first study applying the MBR method to estimating fluxes of SOCs to a terrestrial surface and showing the most direct evidence yet of the filter effect of forest canopies for gaseous SOCs.

\section{Supplementary material}

Information on sampling site and events; detection limits and recoveries; back-trajectories and wind-rose diagrams; vertical profiles and particle-bound percentages for all PAHs; regression parameters, fitting curves and discussion of gas/particle partitioning; diurnal cycles of the diffusivity, gradient, and flux. This material is available free of charge at: http://www.atmos-chem-phys.net/8/4105/2008/ acp-8-4105-2008-supplement.pdf.

Acknowledgements. This work was financially supported by the Canadian Foundation for Climate and Atmospheric Sciences (Project GR-007). We further thank S. Hayward and T. Dermott for help with collecting samples, M. S. McLachlan for valuable comments on the manuscript, and J. Fuentes for advice on the setup of the micrometeorological technique.

Edited by: J. Rinne

\section{References}

Böhme, F., Welsch-Pausch, K., and McLachlan, M. S.: Uptake of airborne semivolatile organic compounds in agricultural plants: Field measurements of interspecies variability, Environ. Sci. Technol., 33, 1805-1813, 1999.

Brubaker Jr., W. W. and Hites, R. A.: OH reaction kinetics of polycyclic aromatic hydrocarbons and polychlorinated dibenzop-dioxins and dibenzofurans, J. Phys. Chem. A, 102, 915-921, 1998. 
Businger, J. A.: Evaluation of the accuracy with which dry deposition can be measured with current micrometeorological techniques, J. Climate Appl. Meteor., 25, 1100-1124, 1986.

Doskey, P. V., Kotamarthi, V. R., Fukui, Y., Cook, D. R., Breitbeil III, F. W., and Wesely, M. L.: Air-surface exchange of peroxyacetyl nitrate at a grassland site, J. Geophys. Res., 109, D10310, doi:10.1029/2004JD004533, 2004.

Fuentes, J. D., Gillespie, T. J., Den Hartog, G., and Neumann, H. H.: Ozone deposition onto a deciduous forest during dry and wet conditions, Agr. Forest Meteorol., 62, 1-18, 1992.

Fuentes, J. D., Wang, D., Den Hartog, G., Neumann, H. H., Dann, T. F., and Puckett, K. J.: Modelled and field measurements of biogenic hydrocarbon emissions from a Canadian deciduous forest, Atmos. Environ., 29, 3003-3017, 1995.

Fuentes, J. D., Wang, D., Neumann, H. H., Gillespie, T. J., Den Hartog, G., and Dann, T. F.: Ambient biogenic hydrocarbons and isoprene emissions from a mixed deciduous forest, J. Atmos. Chem., 25, 67-95, 1996.

Gu, L., Fuentes, J. D., Shugart, H. H., Staebler, R. M., and Black, T. A.: Responses of net ecosystem exchanges of carbon dioxide to changes in cloudiness: results from two North American deciduous forests, J. Geophys. Res., 104, 31 421-31 434, 1999.

Horstmann, M. and McLachlan, M. S.: Atmospheric deposition of semivolatile organic compounds to two forest canopies, Atmos. Environ., 32, 1799-1809, 1998.

Howsam, M., Jones, K. C., and Ineson, P.: Dynamics of PAH deposition, cycling and storage in a mixed-deciduous (Quercusfraxinus) woodland ecosystem, Environ. Pollut., 113, 163-176, 2001a.

Howsam, M., Jones, K. C., and Ineson, P.: PAHs associated with the leaves of three deciduous tree species - II: Uptake during a growing season, Chemosphere, 44, 155-164, 2001b.

Kurt-Karakus, P. B., Bidleman, T. F., Staebler, R. M., and Jones, K. C.: Measurement of DDT fluxes from a historically treated agricultural soil in Canada, Environ. Sci. Technol., 40, 45784585, 2006.

Kwok, E. S. C., Harger, W. P., Arey, J., and Atkinson, R.: Reactions of gas-phase phenanthrene under simulated atmospheric conditions, Environ. Sci. Technol., 28, 521-527, 1994.

Lee, X. H., Fuentes, J. D., Staebler, R. M., and Neumann, H. H.: Long-term observation of the atmospheric exchange of $\mathrm{CO}_{2}$ with a temperate deciduous forest in southern Ontario, Canada., J. Geophys. Res., 104, 15 975-15 984, 1999.

Lei, Y. D., Chankalal, R., Chan, A., and Wania, F.: Supercooled liquid vapor pressures of the polycyclic aromatic hydrocarbons, J. Chem. Eng. Data, 47, 801-806, 2002.

Lindberg, S. E., Hanson, P. J., Meyers, T. P., and Kim, K.-H.: Air/surface exchange of mercury vapor over forests - the need for a reassessment of continental biogenic emissions, Atmos. Environ., 32, 895-908, 1998.

MacLeod, M., Scheringer, M., Podey, H., Jones, K. C., and Hungerbühler, K.: The origin and significance of short-term variability of semivolatile contaminants in air, Environ. Sci. Technol., 41, 3249-3253, 2007.

Majewski, M. S., Glotfelty, D. E., Paw, U. K. T., and Seiber, J. N.: A field comparison of several methods for measuring pesticide evaporation rates from soil, Environ. Sci. Technol., 24, 14901497, 1990.
Makar, P. A., Fuentes, J. D., Wang, D., Staebler, R. M., and Wiebe, H. A.: Chemical processing of biogenic hydrocarbons within and above a temperate deciduous forest, J. Geophys. Res., 104, 3581-3603, 1999.

Matzner, E.: Annual rates of deposition of polycyclic aromatic hydrocarbons in different forest ecosystems, Water Air Soil Pollut., 21, 425-434, 1984.

McLachlan, M. S. and Horstmann, M.: Forests as filters of airborne organic pollutants: a model, Environ. Sci. Technol., 32, 413-420, 1998.

McLachlan, M. S.: Framework for the interpretation of measurements of SOCs in plants, Environ. Sci. Technol., 33, 1799-1804, 1999.

Meyers, T. P., Hall, M. E., Lindberg, S. E., and Kim, K.-H.: Use of the modified Bowen-ratio technique to measure fluxes of trace gases, Atmos. Environ., 30, 3321-3329, 1996.

Perlinger, J. A., Tobias, D. E., Morrow, P. S., and Doskey, P. V.: Evaluation of novel techniques for measurement of air-water exchange of persistent bioaccumulative toxicants in Lake Superior, Environ. Sci. Technol., 39, 8411-8419, 2005.

Schween, J. H., Dlugi, R., Hewitt, C. N., and Foster, P.: Determination and accuracy of VOC-fluxes above the pine/oak forest at Castelporziano, Atmos. Environ., 31(SI), 199-215, 1997.

Simonich, S. L. and Hites, R. A.: Vegetation-atmosphere partitioning of polycyclic aromatic hydrocarbons, Environ. Sci. Technol., 28, 939-943, 1994a.

Simonich, S. L. and Hites, R. A.: Importance of vegetation in removing polycyclic aromatic hydrocarbons from the atmosphere, Nature, 370, 49-51, 1994b.

Simonich, S. L. and Hites, R. A.: Organic pollutant accumulation in vegetation, Environ. Sci. Technol., 29, 2905-2914, 1995.

Strong, C., Fuentes, J. D., and Baldocchi, D.: Reactive hydrocarbon flux footprints during canopy senescence, Agr. Forest Meteorol., 127, 159-173, 2004.

$\mathrm{Su}$, Y. and Wania, F.: Does the forest filter effect prevent semivolatile organic compounds from reaching the Arctic?, Environ. Sci. Technol., 39, 7185-7193, 2005.

Su, Y., Lei, Y. D., Wania, F., Shoeib, M., and Harner, T.: Regressing gas/particle partitioning data for polycyclic aromatic hydrocarbons, Environ. Sci. Technol., 40, 3558-3564, 2006.

Su, Y., Wania, F., Harner, T., and Lei, Y. D.: Deposition of polybrominated diphenyl ethers, polychlorinated biphenyls, and polycyclic aromatic hydrocarbons to a boreal decidous forest, Environ. Sci. Technol., 41, 534-540, 2007.

Wania, F. and McLachlan, M. S.: Estimating the influence of forests on the overall fate of semivolatile organic compounds using a multimedia fate model, Environ. Sci. Technol., 35, 582-590, 2001.

Wesely, M. L. and Hicks, B. B.: A review of the current status of knowledge on dry deposition, Atmos. Environ., 34, 2261-2282, 2000.

Xiao, H. and Wania, F.: Is vapor pressure or the octanol-air partition coefficient a better descriptor of the partitioning between gas phase and organic matter?, Atmos. Environ., 37, 2867-2878, 2003. 